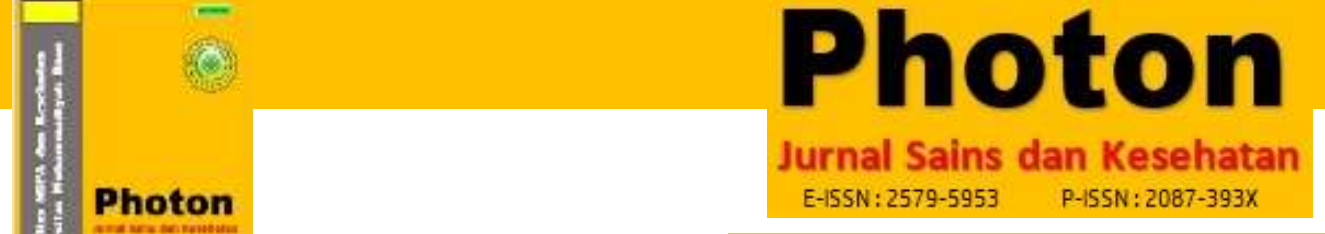

http://ejurnal.umri.ac.id/index.php/photon

\title{
Aktivitas Antioksidan Teh Herbal Dari Campuran Daging Buah Pare (Momordica charantia L.), Jahe M erah (Zingiber officinalle Roscoe) Dan Temulawak (Curcuma xanthorrhiza Roxb)
}

\author{
M usyirna Rahmah N st ${ }^{1 *}$, Syamira ${ }^{2}$ \\ 1,2*Sekolah Tinggi IImu Farmasi Riau; Pekanbaru 28423 \\ Corespodence Email: musyirnarahmah@stifar-riau.ac.id
}

\begin{abstract}
Herbal tea is a formulation of herbal flowers, seeds, leaves, roots, and bark of various plants. It has affectiveness in ener gizing, healing constipation and approving immune. It has been done an experiment of antioxidant activity of herbal tea from the mixture of bitter melon (Momordica charantia L), red ginger (Zingiber officinaleRoscoe) and curcuma (Curcuma xanthorrhiza Roxb). The purpose of this experiment is to make formulation of herbal tea that has strong antioxidant activity and preferably from a mixture of bitter melon (M omordica charantia L), red ginger (Zingiber officinale Roscoe) and curcuma (Curcumaxanthorrhiza Roxb) that has been dried at a temperature of $50-60^{\circ} \mathrm{C}$. The activity of antioxidant is measured by DPPH method, meanwhile organoleptic is analyzed by hedonic method. The result of the experiment from 4 formulations indicates that high antioxidant activity is FIII based on analysis one way AN OV A and Tukey test $99 \%$ true. The compositions of FIII are 1,25 g bitter melon, 0,375 g red ginger and 0,375 g curcuma has high antioxidant in $97,25 \%$. Hedonic test indicates FIII in liking category after added $2 \mathrm{~g}$ palm sugar and $5 \mathrm{~mL}$ lemon.
\end{abstract}

Keywords : Herbal Tea, Antioxidant, Hedonic, DPPH

ABSTRAK

Teh herbal adalah formulasi bunga herbal, biji, daun, akar, dan kulit berbagai tanaman. Ini memiliki efektivitas dalam memberi energi, menyembuhkan sembelit, dan menyetujui kekebalan tubuh. Telah dilakukan percobaan aktivitas antioksidan teh herbal dari campuran pare (M omordica charantia L), jahe merah (Zingiber officinale Roscoe) dan temulawak (Curcuma xanthorrhiza Roxb). Tujuan dari penelitian ini adalah membuat formulasi teh herbal yang memiliki aktivitas antioksidan kuat dan lebih disukai dari campuran pare (Momordica charantia L), jahe merah (Zingiber officinale Roscoe) dan temulawak (Curcuma xanthorrhiza Roxb) yang telah dikeringkan di suhu $50-60^{\circ} \mathrm{C}$. A ktivitas antioksidan diukur dengan metode DPPH, sedangkan organoleptik dianalisis dengan metode hedonis. Hasil percobaan dari 4 formulasi menunjukkan bahwa aktivitas antioksidan tinggi adalah FIII berdasarkan analisis AN OV A satu arah dan uji Tukey 99\% benar. Komposisi FIII adalah 1,25 g pare, 0,375 g jahemerah dan 0,375 g temulawak memiliki antioksidan tinggi 97,25\%. Tes hedonik menunjukkan FIII dalam kategori suka setelah menambahkan $2 \mathrm{~g}$ gula aren dan $5 \mathrm{~mL}$ lemon.

Kata Kunci : The Herbal, Antioksidan, Hedonis, DPPH

\section{Introduction}

Radikal bebas adalah molekul atau atom yang mempunyai elektron tidak berpasangan.Secara alami radikal bebas terbentuk dari proses metabolisme tubuh, radikal bebasjuga dapat terbentuk dari faktor lingkungan seperti asap rokok, penggunaan pestisida pada tumbuhan dan makanan, serta polusi dan radiasi (Tambayong, 1999). Cara mengatasi pengaruh radikal bebas didalam tubuh adalah dengan mengonsumsi senyawa yang bersifat antioksidan. Antioksidan adalah senyawa yang mampu mengenal atau meredam dampak negatif oksidan dalam tubuh. Antioksidan bekerja dengan cara mendonorkan satu elektronnya kepada senyawa yang bersifat oksidan sehingga aktivitas senyawa oksidan tersebut terhambat (Winarsi, 2007).

Tanaman herbal yang berkhasiat untuk mengobati penyakit dapat diperoleh dari buah-buahan dan sayur-sayuran seperti pada famili Cucurbitaceaedan Zingiberaceae (Tjitrosoepomo, 1989). Salah satu tanaman famili Cucubitaceae adalah buah pare (Momordica charantia L). Buah pare (Momordica charantia L) merupakan tanaman daerah beriklim tropis (Riyadi

Received: 12 July 2019, Accepted : 22 M ay 2020 - M ay 2020 - Jurnal Photon V ol.10 N 0.2

DOI : https://doi.org/10.37859/jp.v10i2.1379

PHOTON is licensed under a Creative Commons Attribution-ShareAlike 4.0 International License 


\section{Pembuatan Simplia}

Buah yang telah dikumpulkan dibersihkan dari kotoran-kotoran yang menempel (sortasi basah), dicuci dengan air mengalir sampai bersih, kemudian tiriskan untuk membebaskan buah dari sisa-sisa air cucian. Buah pareyang telah bersih dan bebas dari sisa air cucian kemudian daging buah dipisahkan dari bijinya lalu dirajang tipis $\pm 0,5 \mathrm{~cm}$, sedangkan untuk jahe merah dan temulawak kulit dipisahkan dari daging buahnya lalu dirajang tipis $\pm 0,5 \mathrm{~cm}$. Kemudian dikeringkan dalam oven dengan suhu 50-60ำ selama 24 jam. Simplisia kering dibersihkan kembali dari kotoran yang mungkin tidak hilang pada saat pencucian (sortasi kering). Tahap selanjutnya simplisia kering diblender, disimpan dalam wadah bersih dan tertutup rapat.

\section{Uji Kadar Air}

Penetapan kadar air dilakukan dengan menggunakan alat moisture balance, kerjanya dengan cara menyalakan tombol on/off terlebih dahulu, kemudian piringan diletakan di bagian tengah dan penahan punch di atasnya. Diset program, akurasi maupun temperatur sesuai dengan jumlah simplisia yang diuji. Punch diletakan di atas penyangga, kemudian ditara. Ditimbang serbuk sebanyak $5 \mathrm{~g}$, serbuk simplisia diletakan di atas punch dengan jumlah yang telah disesuaikan. serbuk simplisia diratakan sampai menutupi permukaan punch, lalu ditutup. Setelah proses selesai, maka persen kadar air dari simplisia akan tertera secara otomatis (Anonim, 2000).

\section{Skrining Fitokimia}

Skrining fitokimia untuk senyawa fenolik dilakukan menggunakan $\mathrm{FeCl}_{3}$, flavanoid menggunakan logam $\mathrm{mg}$ dan $\mathrm{HCl}$ pekat, saponin dengan pengocokan, terpenoid dan steroid dengan pereaksi libermann-burchard. Sedangkan untuk alkaloid dilakukan menggunkan pereaksi mayer (Marjoni, 2016 : Hanani, 2016). Pembuatan Teh Herbal Campuran Daging Buah Pare (Momordica charantia L.) Jahe merah (Zingiber officinale Roscoe) dan Temulawak (Curcuma xanthorrhiza Roxb)

Tiap formula memiliki berat $2 \mathrm{~g}$, lalu dimasukan dalam wadah kantong teh.

Tabel 1. Komposisi Bahan-Bahan Untuk Formulasi Teh H erbal

\begin{tabular}{|c|c|c|c|c|}
\hline \multirow{2}{*}{ Formula } & \multicolumn{4}{|c|}{ Jumlah Bahan yang Dicampurkan } \\
\cline { 2 - 5 } & $\begin{array}{c}\text { Buah } \\
\text { Pare } \\
\text { (g) }\end{array}$ & $\begin{array}{c}\text { Jahe } \\
\text { merah } \\
\text { (g) }\end{array}$ & $\begin{array}{c}\text { Temu } \\
\text { lawak } \\
\text { (g) }\end{array}$ & $\begin{array}{c}\text { Air } \\
\text { (ml) }\end{array}$ \\
\hline I & 1,75 & 0,125 & 0,125 & 150 \\
\hline II & 1,5 & 0,25 & 0,25 & 150 \\
\hline III & 1,25 & 0,375 & 0,375 & 150 \\
\hline $\begin{array}{c}\text { IV } \\
\text { (Kontrol) }\end{array}$ & 2 & - & - & 150 \\
\hline
\end{tabular}

Uji A ktivitas Antioksidan

\section{a. Pembuatan Larutan DPPH}

DPPH ditimbang sebanyak $2 \mathrm{mg}$ kemudian dilarutkan dalam $2 \mathrm{~mL}$ metanol sehingga dihasilkan konsentrasi 1000 ppm.

b. Persiapan Sampel

Untuk penyajian tiap formula teh herbal diseduh dengan $150 \mathrm{~mL}$ air panas dan didiamkan selama 5 menit, kemudian teh celup diangkat.

c. Uji Penangkal Radikal DPPH

Uji aktivitas antioksidan dengan metode DPPH yang digunakan seduhan sampel formula FI, FII, FIII, dan FIV (Kontrol), masing-masing diambil $50 \mu \mathrm{L}$ dimasukkan ke dalam plat A, plat B, plat C, dan plat D. Blanko DPPH $50 \mu \mathrm{L}$

Received: 12 July 2019, Accepted : 22 M ay 2020 - M ay 2020 - Jurnal Photon V ol.10 No.2

DOI : https://doi.org/10.37859/jp.v10i2.1379

PHOTON is licensed under a Creative Commons Attribution-ShareAlike 4.0 International License 


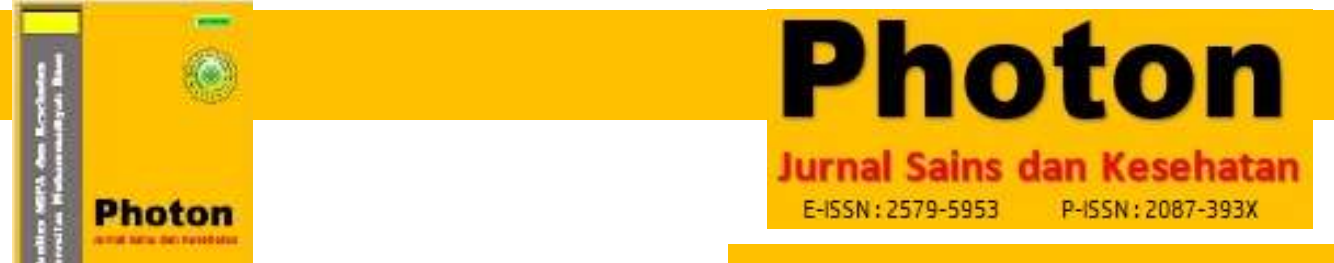

http://ejurnal.umri.ac.id/index.php/photon

metanol (plat E) dan blanko sampel digunakan aquadest $50 \mu \mathrm{L}$ (plat F). Plat A sampai plat E dimasukkan DPPH 80 $\mu \mathrm{L} / \mathrm{mL}$ sebanyak $80 \mu \mathrm{L}$. Tutup plat dengan alumunium foil. Campuran diinkubasi selama 30 menit di tempat gelap pada temperatur ruangan. A bsorban sampel diukur dengan M icroplate reader pada panjang gel ombang $520 \mathrm{~nm}$.

\section{Uji Karakteristik Dari Formula Yang Terpilih}

- Uji pH

Pengukuran $\mathrm{pH}$ dilakukan pada formulasi I, II, III dan IV menggunakan $\mathrm{pH}$ meter. Kalibrasi $\mathrm{pH}$ meter menggunakan larutan dapar fosfat pada pH 4 dan 7. Cuci elektroda dengan air lalu dikeringkan. Celupkan elektroda kedalam masing-masing formulasi, tunggu beberapa menit sampai menunjukkan hasil pH yang konstan ( Anonim, 1985).

\section{- Uji Bobot Jenis}

Pengujian bobot jenis dilakukan pada formulasi I, II, III dan IV menggunakan piknometer. Piknometer dibersihkan dengan akuades lalu dikeringkan, timbang piknometer bobot kosong (W0). Timbang piknometer yang diisi dengan akuades (W 1), timbang piknometer yang diisi dengan formulasi (W2). Bobot jenis dihitung dengan rumus berikut: (Anonim, 1995)

\section{- Uji Viskositas}

$$
B J=\frac{W 2-W 0}{W 1-W 0}
$$

Pengukuran viskositas menggunakan viskometer ostwald, caranya bersihkan viskometer yang akan digunakan lalu dikeringkan, masukkan formulasi melalui tabung A kemudian dihisap agar masuk ketabung B tepat sampai tanda batas lalu siapkan stopwatch sebagai pengukur waktu. Kemudian cairan dibiarkan turun sampai batas garis B. Catat waktu yang dibutuhkan cairan untuk mengalir dari garis A ke garus B. Viskometer dicuci bersih lalu dikeringkan kembali, ulangi cara kerja diatas dengan menggunakan cairan pembanding (akuades) dan dihitung bobot jenis cairan dengan menggunakan piknometer.

$H$ itung viskositas cairan dengan rumus ( $M$ artin et al,1993) :

$$
\frac{\eta 1}{\eta 2}=\frac{\rho 1 . T 1}{\rho 2 . T 2}
$$

- Uji Sifat Organoleptik dengan M etode H edonik

Uji hedonik terhadap formula terpilih dilakukan terhadap panelis sebanyak 10 orang usia $18-25$ tahun diminta mencicipi sampel dan diantara masing-masing pencicipan sampel diharuskan mengonsumsi air minum sebagai penetral, kemudian panelis diminta mengisi kuisioner. Uji organoleptik dilakukan dengan skala hedonik terhadap formula minuman yang memiliki aktivitas antioksidan yang tertinggi, dengan perlakukan penambahan gula merah $2 \mathrm{~g}$ dan lemon $5 \mathrm{~mL}$.

\section{Analisa Data}

Persen inhibisi dihitung dengan rumus

$$
\% \text { Inhibisi }=\frac{\left(A C_{1}-A C_{0}\right)-\left(A S_{1}-A S_{0}\right)}{\left(A C_{1}-A C_{0}\right)} \times 100 \%
$$

Kemudian data dianalisa menggunakan One Way Analylis of Variance(ANOVA) dan metode Tukey.

Received: 12 July 2019, Accepted : 22 M ay 2020 - M ay 2020 - Jurnal Photon V ol.10 No.2

DOI : https://doi.org/10.37859/jp.v10i2.1379

PHOTON is licensed under a Creative Commons Attribution-ShareAlike 4.0 International License 
Photon

http://ejurnal.umri.ac.id/index.php/photon

Tabel 3. Hasil Uji Aktivitas Antioksidan dari Teh Herbal Daging Buah Pare (Momordica charantia L.) Jahe merah (Zingiber officinaleRoscoe) dan Temulawak (Curcumaxanthorrhiza Roxb)

\begin{tabular}{|c|c|}
\hline Formula & \% Inhibisi* \\
\hline FI & $95,489 \pm 0,781$ \\
\hline FII & $90,979 \pm 0,659$ \\
\hline FIII & $97,259 \pm 0,863$ \\
\hline FIV (Kontrol) & $74,397 \pm 0,788$ \\
\hline
\end{tabular}

*Replikasi 3 kali pengulangan

Hasil uji aktivitas antioksidan tertinggi dapat dilihat pada Table 3. Persen inhibisi ini dilanjutkan dengan analisis menggunakan one way ANOVA dengan metode Tukey diperoleh hasil formula FIII berbeda sangat nyata $(p<0,05)$ dengan formula FI, formula FII, dan formula FIV . Formula yang memiliki aktivitas antioksidan yang tertinggi dilanjutkan pada uji karakteristik. Uji karakteristik dari penelitian ini yaitu:

Uji pH dari setiap formula yaitu formula I 4,67, formula II 4,58, formula III 4,70 dan formula IV 5,28. Pemeriksaan pH bertujuan untuk mengetahui stabilitas dan keamanan sediaan untuk kesehatan tubuh, dimana pH yang aman untuk kesehatan tubuh berkisar antara 4-7 (Anonim, 1985).

Uji bobot jenis tujuannya agar mengetahui apakah sediaan bisa mengalir dengan baik dan mudah dituang, karena BJ air akan mudah dituang dan mengalir dengan baik. $\mathrm{H}$ asil pemeriksaan menunjukkan bahwa semua sampel menghasilkan BJ air yaitu 1. Sediaan yang berbentuk cairan jernih BJ nya akan 1 karena sudah sesuai dengan ketentuan standar (A nonim, 1985).

Uji viskositas tujuannya untuk menentukan nilai kekental an atau cairan dari suatu zat dan untuk melihat apakah terjadi peningkatan atau penurunan pada viskositas. Semakin tinggi nilai viskositas maka semakin tinggi tingkat kekentalan suatu zat tersebut. $\mathrm{H}$ asil yang didapatkan setiap sampel sama yaitu $0,89 \mathrm{cp}$, setiap bobot jenis yang dihasilkan besar maka viskositasnya juga akan meningkat, dan apabila bobot jenisnya kecil maka viskositasnya akan kecil atau bernilai tetap (M artin et al, 1993).

Uji organoleptik pada penelitian ini digunakan metode afektif. M etode afektif merupakan metodeyang digunakan untuk mengukur sikap subjektif konsumen terhadap produk berdasarkan sifat-sifat organoleptik (A nonim, 2006). Adapun uji yang dipilih pada metode afektif adalah uji hedonik.

Uji hedonik merupakan pengujian yang paling banyak digunakan untuk mengukur tingkat kesukaan terhadap produk. Uji hedonik dilakukan terhadap formula teh herbal yang memiliki aktivitas antioksidan yang tertinggi yang diberikan perlakukan dengan penambahan lemon $5 \mathrm{~mL}$ dan gula merah $2 \mathrm{~g}$. Uji hedonik ini menggunakan panelis sebanyak 10 orang dengan rentang usia 18-25 tahun. Rentang usia ini dipilih berdasarkan tujuan dan manfaat dari teh herbal ini yaitu sebagai minuman pencegahan diusia dini sehingga dapat mengurangi resiko terjadinya penyakit degeneratif akibat paparan radikal bebas (Santika, 2015). Hasil uji hedonik dari 10 panelis terhadap teh herbal dari formula terpilih yaitu formula FIII dengan perlakuan dengan tambahan lemon, gula merah dan campuran keduanya.

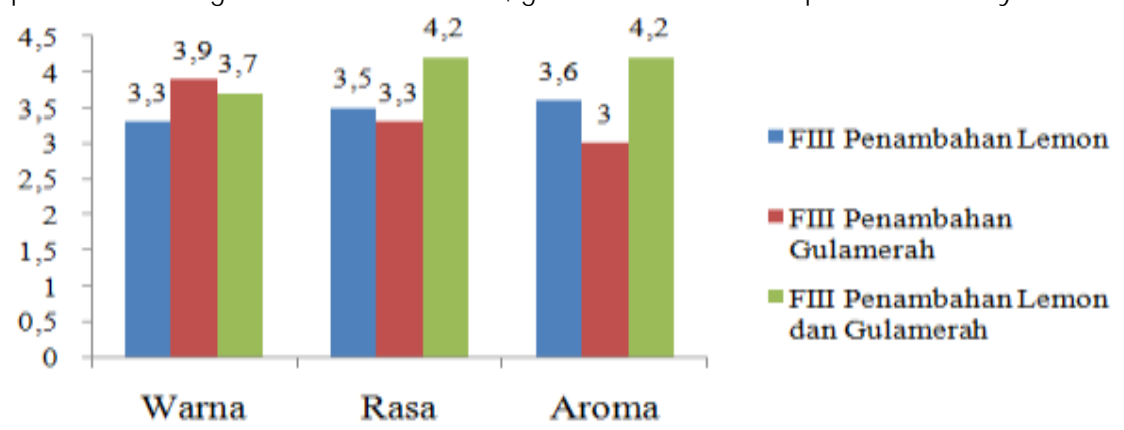

Gambar 1. Diagram Batang Uji H edonik Teh H erbal Daging Buah Pare(Momordica charantiaL.) Jahe merah (Zingiber officinaleRoscoe) dan Temulawak (Curcumaxanthorrhiza Roxb)

Received: 12 July 2019, Accepted : 22 M ay 2020 - M ay 2020 - Jurnal Photon V ol.10 N 0.2

DOI : https://doi.org/10.37859/jp.v10i2.1379

PHOTON is licensed under a Creative Commons Attribution-ShareAlike 4.0 International License 
